BNL-113209-2016-JA

\title{
Evaluation of Oxygen Reduction Activity by the Thin-Film Rotating Disk Electrode Methodology: the Effects of Potentiodynamic Parameters
}

\author{
Guangyu Chen, Meng Li, Kurian A. Kuttiyiel, \\ Kotaro Sasaki, Fanpeng Kong, Chunyu Du, \\ Yunzhi Gao, Geping Yin, Radoslav R. Adzic
}

Submitted to Electrocatalysis

July 2016

Chemistry Department

Brookhaven National Laboratory

\author{
U.S. Department of Energy \\ USDOE Office of Science (SC), \\ Basic Energy Sciences (BES) (SC-22)
}

Notice: This manuscript has been authored by employees of Brookhaven Science Associates, LLC under Contract No. DE- SC0012704 with the U.S. Department of Energy. The publisher by accepting the manuscript for publication acknowledges that the United States Government retains a non-exclusive, paid-up, irrevocable, world-wide license to publish or reproduce the published form of this manuscript, or allow others to do so, for United States Government purposes. 


\section{DISCLAIMER}

This report was prepared as an account of work sponsored by an agency of the United States Government. Neither the United States Government nor any agency thereof, nor any of their employees, nor any of their contractors, subcontractors, or their employees, makes any warranty, express or implied, or assumes any legal liability or responsibility for the accuracy, completeness, or any third party's use or the results of such use of any information, apparatus, product, or process disclosed, or represents that its use would not infringe privately owned rights. Reference herein to any specific commercial product, process, or service by trade name, trademark, manufacturer, or otherwise, does not necessarily constitute or imply its endorsement, recommendation, or favoring by the United States Government or any agency thereof or its contractors or subcontractors. The views and opinions of authors expressed herein do not necessarily state or reflect those of the United States Government or any agency thereof. 


\title{
Evaluation of Oxygen Reduction Activity by the Thin-Film Rotating Disk Electrode Methodology: The Effects of Potentiodynamic Parameters
}

\author{
Guangyu Chen ${ }^{1,2}$, Meng Li $^{2}$, Kurian A. Kuttiyiel ${ }^{2}$, Kotaro Sasaki ${ }^{2}$, Fanpeng Kong ${ }^{1}$, \\ Chunyu $\mathrm{Du}^{1}$, Yunzhi Gao ${ }^{1}$, Geping Yin ${ }^{1 *}$, Radoslav R. Adzic ${ }^{2 *}$
}

${ }^{1}$ State Key Laboratory of Urban Water Resource and Environment, School of Chemical
Engineering and Technology, Harbin Institute of Technology, Harbin 150001, China
${ }^{2}$ Chemistry Department, Brookhaven National Laboratory, Upton, NY 11973, USA

\begin{abstract}
An accurate and efficient assessment of activity is critical for the research and development of electrocatalysts for oxygen reduction reaction (ORR). Currently the methodology combining the thin-film rotating disk electrode (TF-RDE) and potentiodynamic polarization is the most commonly used to pre-evaluate ORR activity, acquire kinetic data (i.e., kinetic current, Tafel slope, etc.) and gain understanding of the ORR mechanism. However, it is often neglected that appropriate potentiodynamic parameters have to be chosen to obtain reliable results. We first evaluate the potentiodynamic and potentiostatic polarization measurements with TF-RDE to examine the ORR activity of Pt nano-electrocatalyst. Furthermore, our results demonstrate that besides depending on the nature of electrocatalyst, the apparent ORR kinetics also strongly depends on the associated potentiodynamic parameters, such as scan rate and the scan region, which have a great effect on the coverage of adsorbed $\mathrm{OH}_{\mathrm{ad}} / \mathrm{O}_{\mathrm{ad}}$ on Pt surface, thereby affecting the ORR activities of both nano-sized and bulk Pt. However, the apparent Tafel slopes remained nearly the same, indicating that the ORR mechanism in all the measurements was not affected by different potentiodynamic parameters.
\end{abstract}

Keywords: ORR, TF-RDE, electrocatalyst, catalytic activity, potentiodynamic parameters

*To whom correspondence should be addressed:

Emails: yingphit@hit.edu.cn; adzic@bnl.gov 


\section{Introduction}

The commercialization of proton exchange membrane fuel cells (PEMFCs) has been impeded by the sluggish kinetics of oxygen reduction reaction (ORR) occurring at the fuel cell cathode, as well as the high cost of Pt containing electrocatalysts [1-4]. Previous studies combining electrochemical and ultra-high vacuum (UHV) techniques with theoretical density functional theory (DFT) calculations have identified that the high activation overpotential and the slow kinetics for ORR on Pt surface are caused by strongly adsorbed oxygenated species (i.e., $\mathrm{OH}_{\mathrm{ad}} / \mathrm{O}_{\mathrm{ad}}$ ), which block the active sites for $\mathrm{O}_{2}$ adsorption, splitting of the O-O bond, and reduction to $\mathrm{H}_{2} \mathrm{O}$ [4-13]. Although the true origin of these oxygenated species has yet to be confirmed, several researchers proposed that they were not derived from ORR, but rather from the oxidation of $\mathrm{H}_{2} \mathrm{O}$ molecules in aqueous electrolyte or hydrated-solid electrolyte interface [4, 11, 14]. Moreover, the intrinsic kinetic reaction rate of ORR is not limited by the rate determining step itself, but is limited by potential determining the surface coverage of $\mathrm{OH}_{\mathrm{ad}} / \mathrm{O}_{\mathrm{ad}}$, which is the so-called Pt self-poisoning effect $[4,15]$. Therefore, intensive research efforts are devoted to the development of high-activity ORR electrocatalysts with moderately weaker adsorption of $\mathrm{OH}_{\mathrm{ad}} / \mathrm{O}_{\mathrm{ad}}$ and lower cost $[4,6,8,9,12,16]$.

To develop improved electrocatalysts for ORR, it is necessary to understand the kinetics and quantitatively determine their electrocatalytic activities. One approach is to prepare a membrane electrode assembly (MEA) and then to determine the ORR activity under practical operating conditions of PEMFCs in single fuel cell setup. However, a large amount of electrocatalyst is needed for MEA preparation, and it is difficult to extract the intrinsic ORR kinetic parameters because several other factors come into play, such as the limitations of fabrication technique of MEA, uncertain operating conditions, and the influence from mass-transfer processes and other components of MEA [17]. Currently, the thin-film rotating disk electrode (TF-RDE) technique has been widely used to measure the ORR activities of nano-sized electrocatalysts due to the simple experimental procedures, minor quantity of electrocatalyst needed and the efficient and direct activity evaluation. In TF-RDE system, other factors can be excluded and the $\mathrm{O}_{2}$ transport can be well controlled by electrode rotating speed in a three-electrode cell [3, 17-19]. Based on the diffusion model of smooth surface, the intrinsic ORR kinetic current of electrocatalyst could be derived directly from the measured 
oxygen reduction current density at a certain electrode rotating speed (e.g., $1600 \mathrm{rpm}$ ) in $\mathrm{O}_{2}$-saturated electrolyte according to the well-known Koutecký-Levich (K-L) equation [5, 20]. For comparison reason, the ORR kinetic current is generally normalized to the loading or the electrochemical surface area (ECSA) of Pt to obtain the mass activity (MA) and specific activity (SA). Although the TF-RDE method itself is easy to implement, it is still difficult to perform such a comparison because the measured ORR activities can be affected largely by the factors associated experimental aspects, as evidenced by the contradictory results reported in literatures [21]. Previously, the effects of the preparation procedures of electrocatalyst thin-film (i.e., ink formula, electrocatalyst loading, quality of thin-film) and operating conditions (i.e., temperature, electrolyte type, impurities level in electrolyte) on the ORR activities of nano-sized electrocatalysts have been investigated [18, 19, 21-27]. However, the effects of electrochemical characterization itself are often neglected. Recently, preliminary studies of the effects of potentiodynamic parameters on the apparent ORR activities have been reported for bulk Pt electrode [28, 29], nonetheless, the results still warrant further investigation, especially for nano-sized electrocatalyst.

In this work, we carried out systemic investigation of the impacts of potentiodynamic polarizarion parameters on electrocatalytic ORR kinetics on a commercial carbon-supported Pt catalyst, using TF-RDE method. Electrochemical polarization methods, inevitable errors caused by TF-RDE system, and the reliability of measured results were discussed in detail. Unexpectedly, the measured results showed strong dependency on the potentiodynamic parameters. However, the apparent Tafel slopes at low current densities remained nearly the same, about -62 65 $\mathrm{mV} \operatorname{dec}^{-1}$. In addition, to exclude the possibility of this experimental phenomenon being caused by thin-porous electrocatalyst film, the polarization behavior of bulk Pt for ORR was also studied. The identical experimental phenomena were also found on bulk Pt surface. Furthermore, on the basis of this work, the potentiodynamic parameters for accurate prediction the ORR activities of electrocatalyst in MEA-PEM fuel cells were provided.

\section{Experimental}

The commercial carbon-supported Pt (20 wt\% Pt/C, E-TEK, Lot \# E0350128, mean particle 
size $4 \mathrm{~nm}$ ) was used. This nano-sized electrocatalyst was dispersed in mixture of ultrapure water (Milli-Q UV-plus, 18.2 M $\Omega \mathrm{cm} @ 25^{\circ} \mathrm{C}$ ) and isopropanol (3:1, Nafion free) by sonication to form a dark and uniform suspension. A thin-electrocatalyst film was prepared on a polished glassy carbon RDE (5 mm diameter, Pine Instruments) by drop-casting this suspension. The Pt

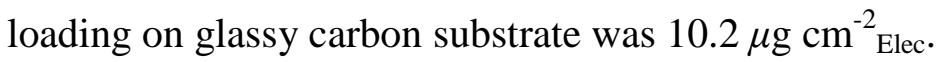

Electrochemical measurements were carried out at room temperature in a three-electrode electrolytic cell with Pt foil as counter electrode and double junction $\mathrm{Ag} / \mathrm{AgCl} / \mathrm{NaCl}(3 \mathrm{M})$ as reference electrode. The electrode was first scanned in potential between 0.05 and $1.20 \mathrm{~V}$, with scan rate of $50 \mathrm{mV} \mathrm{s}^{-1}$ in $\mathrm{Ar}(5 \mathrm{~N})$-saturated $0.1 \mathrm{M} \mathrm{HClO}_{4}(\mathrm{aq})$ solution for several cycles until stable voltammetric curves were obtained. Then, the $0.1 \mathrm{M} \mathrm{HClO}_{4}(\mathrm{aq})$ solution was replaced by a fresh one for the following measurements. The ORR experiments were undertaken in $\mathrm{O}_{2}$ (research purity) -saturated $0.1 \mathrm{M} \mathrm{HClO}_{4}(\mathrm{aq})$ at the electrode rotating speed of $1600 \mathrm{rpm}$.

A series of stable ORR polarization curves were recorded using different potentiodynamic parameters: 1) the scan rates from 5 to $50 \mathrm{mV} \mathrm{s}^{-1}$ in same potential scan region $(0.05-1.03 \mathrm{~V}$, the high potential limit, $1.03 \mathrm{~V}$, refers to the open circuit potential (OCP)); 2) the potential scan region from $0-0.60$ to $1.03 \mathrm{~V}$ with same scan rate $\left(10 \mathrm{mV} \mathrm{s}^{-1}\right)$; 3$)$ the scan region from 0.05 to 0.90-1.20 V with same scan rate $\left(10 \mathrm{mV} \mathrm{s}^{-1}\right)$. In order to confirm that changes of recorded ORR currents under different potentiodynamic parameters are not as a result of the reduction of the ECSA of Pt/C during ORR operating process, and electrolyte contamination, the ORR polarization curves also were recorded in reverse sequence. So the experimental data was reliable.

To eliminate the contribution of background current (including both double layer capacitive current and capacitive current from adsorption/desorption processes on Pt surface) and analyze the ORR results [19], the cyclic voltammograms (CVs) also were recorded in Ar-saturated 0.1 $\mathrm{M} \mathrm{HClO}_{4}(\mathrm{aq})$ with same potentiodynamic parameters of ORR scan profiles. ORR curves were $I R$-corrected using the value of the electrolyte resistance $\left(20 \sim 25 \Omega @ 25^{\circ} \mathrm{C}\right.$ in $0.1 \mathrm{M} \mathrm{HClO}_{4}$ (aq) depends on the distance between Luggin capillary and the surface of TF-RDE|Pt/C) determined from the high frequency part of the electrochemical impedance spectra (measured in the $1 \mathrm{~Hz}$ to $100 \mathrm{kHz}$ range) [30, 31]. At last, the measured currents at $0.9 \mathrm{~V}$ were mass-transfer corrected by K-L equation in order to obtain ORR kinetic currents and catalytic activity of Pt/C. In this 
paper, only the MA was used for comparison, because the SA has similar trends. All the potentials were given with respect to a reversible hydrogen electrode (RHE). The instrument used was CHI 604d electrochemical workstation equipped with Pine rotator.

For comparison, a polycrystalline bulk Pt RDE (5 mm diameter, embedded in a Teflon cylinder, Pine Instruments) was also studied. It was cleaned by polishing with aqueous slurries of successively finer alumina powders (particle size from ca. 0.3 to $0.05 \mu \mathrm{m}$ ) with the help of Buehler ${ }^{\circledR}$ MicroCloth and further cleaned by scanning the potential between the onset potential of the hydrogen and oxygen evolution reactions in Ar-saturated $0.1 \mathrm{M} \mathrm{HClO}_{4}$ (aq) for several cycles until a CV of a clean Pt surface was obtained. A series of ORR polarization curves of bulk Pt were recorded using same potentiodynamic parameters as used for TF-RDE|Pt/C except that ten times higher scan rates were employed. ORR polarization curves of bulk Pt were also processed by background current subtraction and $I R$ drop correction.

\section{Results and discussion}

\subsection{Potentiostatic polarization vs. potentiodynamic polarization}

In the MEA test, ORR activities of electrocatalysts are usually evaluated using the so-called potentiostatic step method, in which pseudo-steady-state $I-V$ polarization curves are recorded by holding the cell voltage or current a series of discrete, decreasing or increasing values for a period of 5-15 min to obtain stable currents or voltages [3, 32]. The results can accurately reflect the ORR activity of the electrocatalyst in MEAs-PEM fuel cell stacks for practical applications. Moreover, the U.S. Department of Energy (DOE) and its partner, the U.S. DRIVE Fuel Cell technical team has established a testing protocol/evaluation criterion for ORR measurement in MEA-PEM fuel cell based on the potentiostatic step method, so it is easy to compare the results from different research groups [33, 34].

It is interesting to identify if the potentiostatic approach can also be used in TF-RDE system, so we carried out the experiment to the TF-RDE|Pt/C by continuously stepping the electrode potential from OCP at $1.03 \mathrm{~V}$ to a series of lower cathode potential or in reverse sequence under ORR operating conditions in three-electrode electrolytic cell. However, unlike in the MEA-fuel cells, the ORR currents cannot reach a stable value at all stepped potential (not 
shown), even with a longer time of $30 \mathrm{~min}$. It is a common convention to use the kinetic current at $0.9 \mathrm{~V}$ to compare the ORR activities of different electrocatalysts. Figure 1a shows a time-dependent ORR polarization curve (red curve) with only one step from 0.20 to $0.90 \mathrm{~V}$. The ORR current density decreases rapidly even after 30 minutes when the electrode potential is held at $0.90 \mathrm{~V}$. Correspondingly, the $\mathrm{MA}$ of $\mathrm{Pt} / \mathrm{C}$ at $0.9 \mathrm{~V}$ changes from 0.50 to $0.03 \mathrm{~A} \mathrm{mg}^{-1} \mathrm{Pt}$ (green curve). Therefore, it is quite difficult for us to judge which value is a good representation of the ORR activity. Moreover, a same trend can be observed whether the potential is stepped from a lower potential or from a higher potential to the holding potential higher than $0.60 \mathrm{~V}$ (operating voltage of PEMFC is $0.6 \sim 1.0 \mathrm{~V}$ ). This means a pseudo-steady-state polarization curve cannot be obtained by potentiostatic step method to determine a reliable catalytic activity in TF-RDE three-electrode cell system. Actually, the ORR currents also decrease at all stepped potentials in MEA-PEM fuel cell test [35-37], but it is relatively slow after 5-10 min so that the pseudo-steady-state current can be extracted. This attenuation can be mainly attributed to the self-poisoning effect, in which electroadsorbed oxygenated species, $\mathrm{OH}_{\mathrm{ad}} / \mathrm{O}_{\mathrm{ad}}$, builds up on catalyst surface during ORR process [38-41]. In addition, the ORR activity will further aggravate due to the continuous accumulation of impurities from electrolyte on electrocatalyst surface, even with the "purest” perchloric acid used [42]. So the pseudo-steady-state cannot be established in TF-RDE system.

Cyclic voltammetry, which controls the electrode potential to change as a linear function of time between two potential points, is a powerful transient-state technique in electrochemical research that provide $I-V$ polarization curve reflecting the electrochemical process on catalyst surface. As shown in Figure 1b, a typical CV profile of Pt/C recorded in Ar-saturated $0.1 \mathrm{M}$ $\mathrm{HClO}_{4}(\mathrm{aq})$ with a scan rate of $50 \mathrm{mV} \mathrm{s}^{-1}$ exhibited two well-defined redox features that correspond to under-potential deposition of hydrogen (H-UPD, $0.05 \sim 0.40 \mathrm{~V}$ ), and the $\mathrm{OH}_{\mathrm{ad}} / \mathrm{O}_{\mathrm{ad}}$ adsorption on Pt surface (0.70 1.03 V). Moreover, the second cycle and tenth cycle of voltammetric curve are coincident totally. It is because the electrode potential changing in cyclic voltammetry is constant with time (i.e., the scan rate, $\mathrm{d} E / \mathrm{d} t=$ const) and is not stepped suddenly from one potential to the other potential. Moreover, the adsorption/desorption oxygenated species on catalyst surface is balanced dynamically and adsorbed trace impurities can be removed continuously during the cyclic scanning process. So the corresponding 
dynamic current response with the successive potential scan can be accurately obtained. Furthermore, by comparing the second and tenth CVs (in Figure 1c) measured at the rotating speed of $1600 \mathrm{rpm}$ in $\mathrm{O}_{2}$-saturated $0.1 \mathrm{M} \mathrm{HClO}_{4}(\mathrm{aq})$ with same potentiodynamic parameters, we find a reliable polarization curve for ORR can be obtained. Our results demonstrated that ORR activities of electrocatalysts in TF-RDE system should be evaluated using the potentiodynamic polarization method, instead of the potentiostatic method. In order to determine the true ORR activity of nano-sized electrocatalyst, two errors from superimposed background current (capacitive current due to adsorption and double-layer charging processes at the electrode surface) and potential drop (IR drop induced by solution resistance) need to be eliminated before calculating the ORR kinetic current [30]. As illustrated in Figure 1d, the blue curve is pure ORR current response obtained by subtracting the CV profile (pink curve) measured in Ar-saturated $0.1 \mathrm{M} \mathrm{HClO}_{4}(\mathrm{aq})$ from the ORR profile (green curve) measured in $\mathrm{O}_{2}$-saturated $0.1 \mathrm{M} \mathrm{HClO}_{4}(\mathrm{aq})$. This procedure involves the so-called a priori separation of faradaic and capacitive currents [43], which cannot be done generally. Nisancioglu and Newman concluded that the effect is not significant for well-supported electrolytes [44]. And then, the electrode potential is corrected by adding the $I R$ drop to the original potential value. The red curve in figure $1 \mathrm{~d}$ is the final $I-V$ polarization curve for ORR.

Through comparison of the ORR curves before and after corrections we find those two errors could pose a considerable impact on ORR activity determination. Furthermore, a large current hysteresis loop was observed at $E>c a .0 .7 \mathrm{~V}$ between the positive-going and negative-going scans in ORR kinetic region. It can be attributed to the irreversible adsorption/desorption of oxygenated species that leads to a large difference in $\mathrm{OH}_{\mathrm{ad}} / \mathrm{O}_{\mathrm{ad}}$ coverage under the same potential in the positive and negative scan directions [45]. Moreover, as indicated in Figure 5a and Figure 6e, the ORR current response in the negative-going scan is dependent on the high potential limit. So the ORR activity of electrocatalyst is commonly extracted from the polarization curve in positive scan direction to avoid the influence from pre-adsorbed $\mathrm{OH}_{\mathrm{ad}} / \mathrm{O}_{\mathrm{ad}}$ on catalyst surface in high potential region [5, 46].

Based on the above analysis, measurement of a reliable $I-V$ polarization curve for ORR in TF-RDE system have to adopt potentiodynamic polarization method of cyclic voltammetry, until a stable and reproducible ORR-scan profile is obtained. Then the positive-going segment 
of cyclic curve, with background current and IR drop corrected, is used as the ORR polarization curve in the further study.
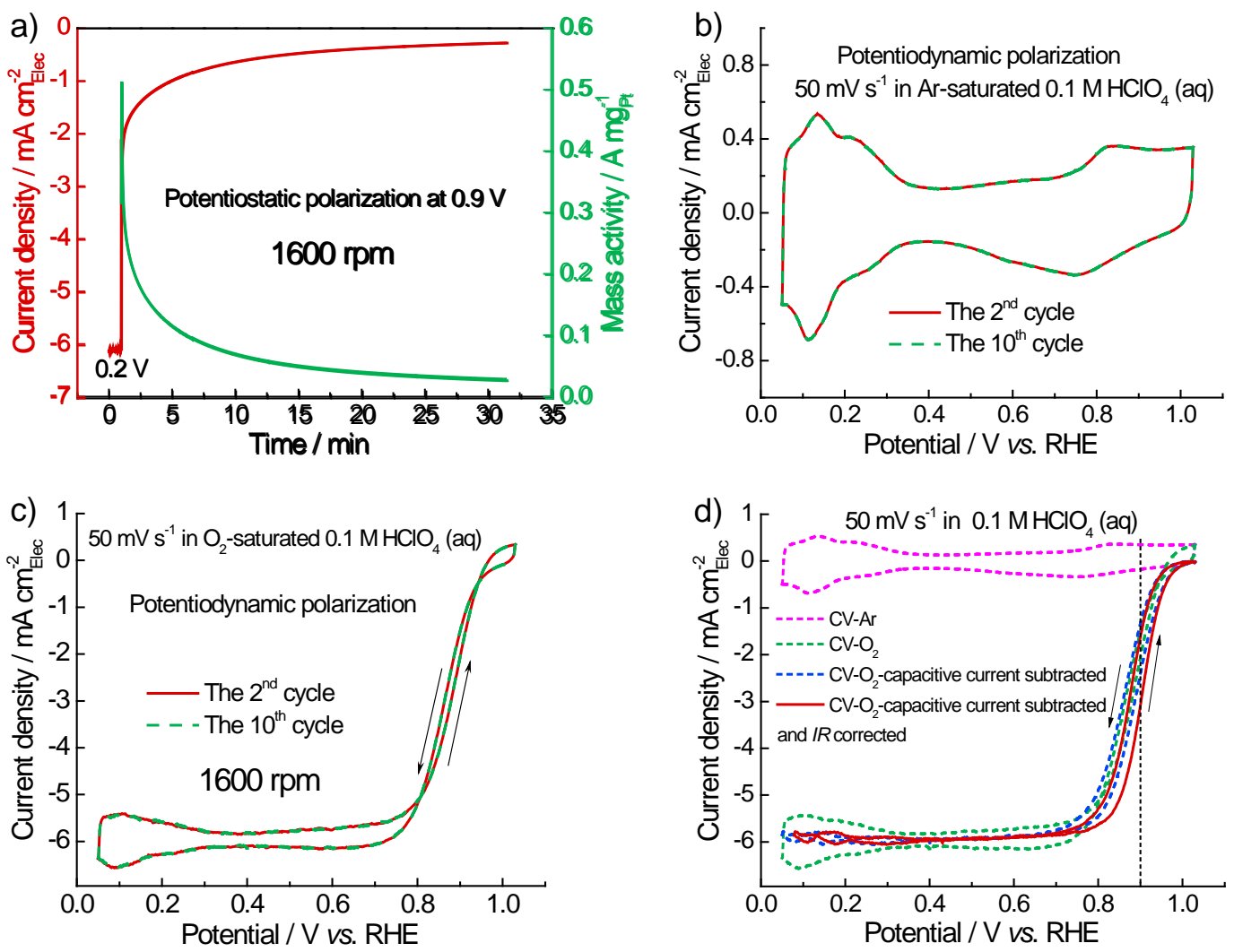

Figure 1. (a) Potentiostatic polarization curve for ORR measured by stepping the potential from 0.20 to 0.90 V. (b) CVs measured at potential scan region between 0.05 and $1.03 \mathrm{~V}$ with a scan rate of $50 \mathrm{mV} \mathrm{s}^{-1}$ in Ar-saturated $0.1 \mathrm{M} \mathrm{HClO}_{4}$ (aq). (c) Potentiodynamic polarization curve for the ORR (without $I R$ correction) measured at potential scan region between 0.05 and $1.03 \mathrm{~V}$ at the electrode rotating speed of $1600 \mathrm{rpm}$ with a scan rate of $50 \mathrm{mV} \mathrm{s}^{-1}$ in $\mathrm{O}_{2}$-saturated $0.1 \mathrm{M} \mathrm{HClO}_{4}$ (aq) solution. (d) Pink curve is as background current from Figure 1b, and green curve is as ORR polarization curve from Figure 1c, blue curve is the ORR polarization curve subtracted background current, red curve is the ORR polarization curve subtracted background current and corrected with $I R$ drop. Working electrode: TF-RDE|Pt/C.

ORR polarization curves on TF-RDE|Pt/C and smooth bulk Pt measured at the same polarization conditions are displayed in Figure 2a, and no significant difference is observed in the diffusion limited current densities, ca. $6 \mathrm{~mA} \mathrm{~cm}^{-2}$ Elec, indicating a moderate loading of $\mathrm{Pt} / \mathrm{C}$ on glassy carbon electrode and the high quality of electrocatalyst thin-film. The catalyst needs to be homogeneously dispersed and covers the whole surface of glassy carbon substrate. Moreover, this film is thin enough so that the resistance of oxygen diffusion inside this thin-film is negligible [17, 21]. 
The ORR polarization curve obtained from Pt/C electrocatalyst shifts positively at $E>c a$. 0.7 V compared to that from bulk Pt, which can be attributed to the larger ECSA in nano-sized Pt/C for ORR. Further, the kinetic current densities in Tafel plot were obtained by mass-transfer correction and then the corresponding apparent Tafel slopes in the potential of $0.85 \mathrm{~V}<E<0.95 \mathrm{~V}$ were also calculated, as displayed in Figure 2b. The apparent Tafel slope of TF-RDE|Pt/C is nearly the same as that of bulk Pt, indicating that the effect of oxygen diffusion from electrolyte to the electrode surface can be completely corrected by the K-L equation. In figure 2b, Tafel slopes are compared just to judge whether or not the mass-transfer of $\mathrm{O}_{2}$ is corrected. Further analysis of the Tafel slope is done in the next section. In addition, the SA of bulk Pt is up to $1.92 \mathrm{~mA} \mathrm{~cm}^{-2}$ ECSA, which is calculated by the kinetic current at $0.9 \mathrm{~V}$ in Figure 2b normalized to its ECSA. This value is in agreement with the literature [46], and can be considered a measure of acceptable cell cleanliness because bulk Pt has a very low roughness factor ( $S_{\text {ECSA }} / S_{\text {Elec }}, \sim 1.8$ based on $210 \mu \mathrm{C}_{\mathrm{H}-\mathrm{UPD}} \mathrm{cm}^{-2}$ Pt in this study) and is highly sensitive to trace impurities in three-electrode electrolytic cell system (glassware and electrolyte). Therefore, the experimental results in this work are reliable.
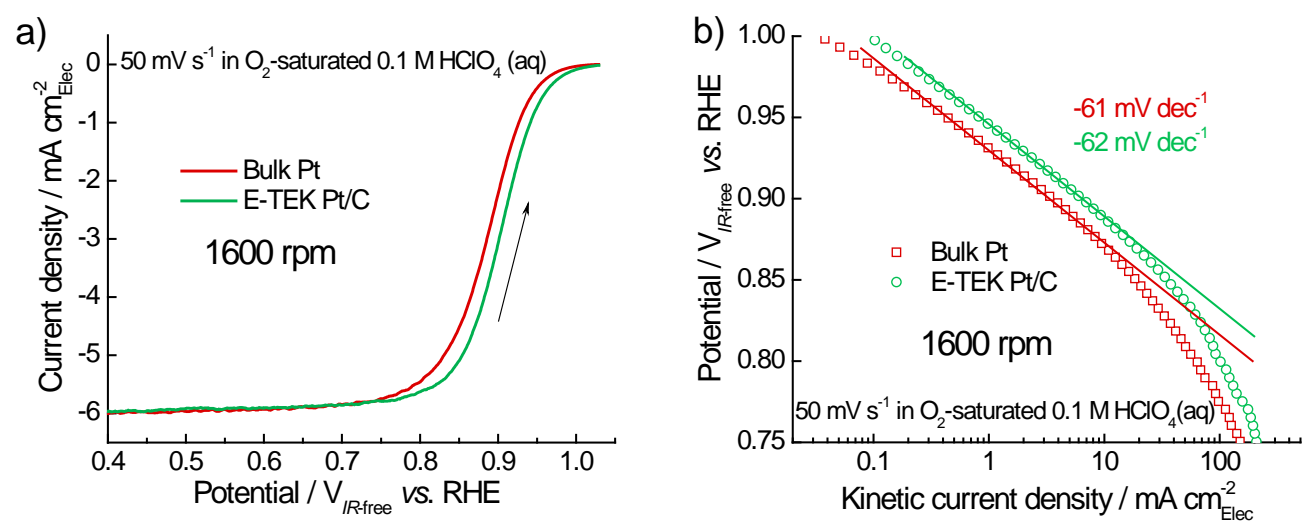

Figure 2. Comparison of the TF-RDE|Pt/C with bulk Pt RDE. (a) ORR polarization curves obtained in potential region between 0.05 to $1.03 \mathrm{~V}$ with a positive scan rate of $50 \mathrm{mV} \mathrm{s}^{-1}$ at the electrode rotating speed of $1600 \mathrm{rpm}$ in $\mathrm{O}_{2}$-saturated $0.1 \mathrm{M} \mathrm{HClO}_{4}$ (aq) and (b) the corresponding Tafel plots.

\subsection{The effects of potentiodynamic parameters on the measurement of ORR activity of nano-sized catalyst}

Although ORR activity of electrocatalysts is now widely evaluated using cyclic voltammetry in TF-RDE three-electrode system, large discrepancy exists in the reported results. 
One example is the reported mass activities of the same commercial electrocatalyst (E-TEK $\mathrm{Pt} / \mathrm{C}, 20 \mathrm{wt} \%$ ) can vary by an order of magnitude [21, 23, 25]. As we briefly discussed in Introduction, in addition to factors like electrode preparation, operating conditions and two sources of error mentioned above, one main reason for the difference in reported ORR activities is the inconsistent potentiodynamic parameters used by TF-RDE method in determination ORR activities of electrocatalysts. In the following sections, we will focus on discussing the effects of potentiodynamic parameters, i.e., the scan rate and scan region in cyclic voltammetry, on the ORR kinetics and activities.

\subsubsection{The effects of scan rate in potentiodynamic polarization (cyclic voltammetry)}

For a better trade-off between the effect of trace impurities, such as chloride anions, even if the "purest" perchloric acid is used, and the effect of capacitive current on nano-sized electrocatalyst [18, 29, 30, 42], most studies are carried out with the scan rate between 5 and 50 $\mathrm{mV} \mathrm{s}^{-1}$ to determine the ORR activities of electrocatalysts. We conducted ORR polarization experiments of TF-RDE|Pt/C with scan rates of 5, 10, 20 and $50 \mathrm{mV} \mathrm{s}^{-1}$. As shown in Figure 3a, the biggest difference between these four ORR curves lies in kinetic region (i.e., ca. $0.7 \mathrm{~V}<E$ $<$ ca. $1.0 \mathrm{~V}$ ), where obvious positive potential shifts with increase of scan rate are observed. A similar trend is also observed in the negative-going polarization curves (not shown). The Tafel plots derived from the corresponding ORR curves are given in Figure 3b. Only the apparent Tafel slopes at low current densities in the potential region of $0.85 \mathrm{~V}<E<0.95 \mathrm{~V}$ were compared in our work because the current densities at $E<0.85 \mathrm{~V}$ are very close the diffusion limited current densities, so that the kinetic current densities calculated from the K-L equation are unauthentic and the Tafel slopes cannot be trusted [18]. The apparent Tafel slopes obtained by linear fitting do not change with increase of scan rate. All slopes are around $-63 \mathrm{mV} \mathrm{dec}{ }^{-1}$, which is roughly equivalent to the $-2.3 \mathrm{RT} / \mathrm{F}\left(-59 \mathrm{mV} \mathrm{dec}^{-1}\right)$ and is in agreement with the value obtained in MEA-PEM fuel cells [3], suggesting that the reaction mechanism remains unchanged because Tafel slope is related to the interaction of the adsorbed oxygenated species with Pt surface [5]. Our result is different from the report from S. V. Mentus et al. [28], and the difference could be caused by the uncorrected $I R$-drop/or electrolyte impurities in their work. In Figure 3c, the calculated MAs for ORR at $0.9 \mathrm{~V}$ demonstrate an activity increase from 0.33 
to $0.66 \mathrm{~A} \mathrm{mg}^{-1}$ Pt when increasing scan rate from 5 to $50 \mathrm{mV} \mathrm{s}^{-1}$. The same trends are also reported in recent published papers [46, 47].

Since the ORR kinetics is suppressed by the electroadsorbed species (i.e., $\mathrm{OH}_{\mathrm{ad}} / \mathrm{O}_{\mathrm{ad}}$ ) derived from oxidation of $\mathrm{H}_{2} \mathrm{O}$ instead of from ORR, it is necessary to investigate the effects of scan rate on the adsorption behavior of $\mathrm{OH}_{\mathrm{ad}} / \mathrm{O}_{\mathrm{ad}}$ in Ar-saturated $0.1 \mathrm{M} \mathrm{HClO}_{4}(\mathrm{aq})$. As shown in Figure 3d, the differential capacity responses of the adsorption of $\mathrm{OH}_{\mathrm{ad}} / \mathrm{O}_{\mathrm{ad}}$ at $E>c a .0 .6 \mathrm{~V}$, obtained by normalizing the currents to respective scan rates, are higher with the decrease of scan rate. Higher capacity for $\mathrm{OH}_{\mathrm{ad}} / \mathrm{O}_{\mathrm{ad}}$ adsorption means a higher coverage of $\mathrm{OH}_{\mathrm{ad}} / \mathrm{O}_{\mathrm{ad}}$ on the Pt surface is associated with a slower scan rate. The coverages of $\mathrm{OH}_{\mathrm{ad}}\left(Q_{\mathrm{OH}} / Q_{\mathrm{H}-\mathrm{UPD}}\right.$, here only the $\mathrm{OH}_{\mathrm{ad}}$ is considered for convenience) as a function of electrode potentials at different scan rates are inserted in Figure 3d. The coverages of $\mathrm{OH}_{\mathrm{ad}}$ at $0.9 \mathrm{~V}$ changed from 0.50 to 0.64 when decreasing scan rate from 50 to $5 \mathrm{mV} \mathrm{s}^{-1}$. A slower scan rate means the electrocatalyst can stay at the potential region of oxidation of $\mathrm{H}_{2} \mathrm{O}$ for longer time during the positive-going scan, because the adsorption/desorption process of oxygenated species on Pt surface are dependent on both electrode potential and polarization time. Thus, the ORR activities of electrocatalysts are dependent on the scan rates.

Based on the result we find the better ORR activity can be measured when the higher scan rate is used. But we must mention for E-TEK Pt/C, ORR activities measured at $0.9 \mathrm{~V}$ are $0.66 \mathrm{~A}$ $\mathrm{mg}^{-1}{ }_{\mathrm{Pt}}$ obtained with a scan rate of $50 \mathrm{mV} \mathrm{s}^{-1}$ in TF-RDE and about $0.11 \mathrm{~A} \mathrm{mg}^{-1} \mathrm{Pt}$ in the MEA-fuel cell [3]. This discrepancy can be attributed to the low utilization of the catalyst particles in MEAs (many particles reside in positions that are not accessible to electrons or protons), and to the different surface coverage of $\mathrm{OH}_{\mathrm{ad}}$ caused by different polarization method, as mentioned in section 3.1. Unlike in MEA-fuel cell, the adsorption process of oxygenated species in potentiodynamic polarization process cannot reach quasi-equilibrium under all scan rates, so that the value of ORR activity from RDE measurement is several times higher than that measured in MEA-fuel cell. But the trends in activity of electrocatalysts in these two systems have been proved to be same and the absolute ORR activities of new electrocatalysts measured under a same scan rate that is used to measure the commercially available Pt/C still are viable to pre-evaluate/predict their electrocatalytic activity in PEMFCs [3, 22, 48].

Based on the factors including the effects of contamination for electrocatalysts, a longer time 
needed to obtain a stable ORR and CV curves at low scan rates and the big discrepancy of ORR activities obtained at high scan rates, we prefer to perform the ORR measurements at a fixed scan rate of $10 \mathrm{mV} \mathrm{s}^{-1}$ to investigate the effects of other potentiodynamic parameters on ORR activities in following study.
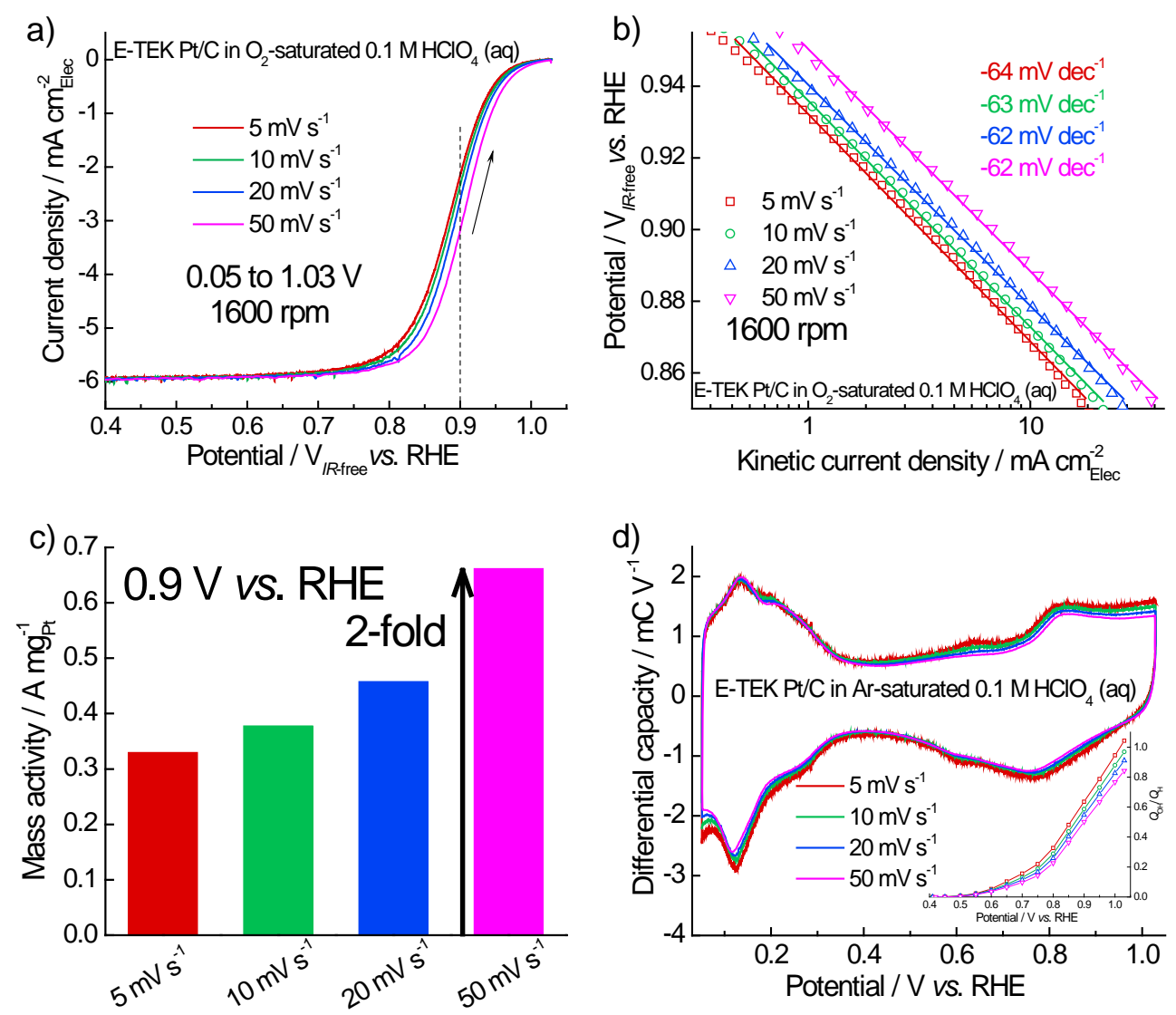

Figure 3. (a) ORR polarization curves and (b) Tafel plots of TF-RDE|Pt/C measured by a positive-going scan from 0.05 to $1.03 \mathrm{~V}$ at the electrode rotating speed of $1600 \mathrm{rpm}$ in $\mathrm{O}_{2}$-saturated $0.1 \mathrm{M} \mathrm{HClO}_{4}$ (aq) with different scan rates. (c) MAs calculated from the current densities at $0.9 \mathrm{~V}$ highlighted by dashed line in Figure 3a. (d) their corresponding CVs with same scan-profiles for ORR polarization measured in Ar-saturated $0.1 \mathrm{M} \mathrm{HClO}_{4}(\mathrm{aq})$, normalized to the scan rates, with the coverages of $\mathrm{OH}_{\mathrm{ad}}$ on the Pt surface as a functional of potential in the inset.

\subsubsection{The effects of scan region in potentiodynamic polarization (cyclic voltammetry)}

Compared with scan rates, the scan region is more easily neglected when using the potentiodynamic polarization to evaluate the ORR activities of electrocatalysts. Therefore, we further investigated its effect. Firstly, we fixed the high potential limit at the OCP, $1.03 \mathrm{~V}$, to investigate the effects of low potential limit on the ORR kinetics of Pt/C. Figure 4a shows ORR 
polarization curves measured with eight different low potential limits from 0 to $0.60 \mathrm{~V}$, in sequence. It can be seen that there was obvious negative potential shift, and the diffusion limited current densities also slightly decreased when the low potential limits were higher than $0.05 \mathrm{~V}$. Moreover, the ORR polarization curves themselves are not stable, and slowly shifted to negative direction with the increase of cyclic numbers (not shown). The corresponding MAs at $0.9 \mathrm{~V}$ are illustrated in Figure 4c, the MAs with low potential limits at 0 and $0.05 \mathrm{~V}$ have almost same value, $0.38 \mathrm{~A} \mathrm{mg}^{-1}$; ; however, the values follow in a descending order with low potential limits from 0.10 to $0.60 \mathrm{~V}$. The maximum MA loss is $72 \%$.

Although the ORR overpotentials increased with the increase of low potential limits, the apparent Tafel slopes (Figure 4b) at $0.85 \mathrm{~V}<E<0.95 \mathrm{~V}$ are still consistent at around $-65 \mathrm{mV}$ $\operatorname{dec}^{-1}$, due to the fact that ORR mechanism is unaffected. Maybe, the differences in ORR activity can still be attributed to the effects of coverage of electroadsorbed species, $\mathrm{OH}_{\mathrm{ad}} / \mathrm{O}_{\mathrm{ad}}$ on the Pt surface. We speculated that not all $\mathrm{OH}_{\mathrm{ad}} / \mathrm{O}_{\mathrm{ad}}$ are desorbed from the Pt surface during the negative-going scan when the low potential limits are higher than $0.05 \mathrm{~V}$. The set of CV curves measured at same scan-profiles with ORR measurements are shown in Figure 4d. The peaks of oxygenated species adsorption at ca. $0.7 \mathrm{~V}<E<c a$. $0.9 \mathrm{~V}$ (highlighted by dashed circle in Figure 4d) are suppressed obviously when low potential limit is higher than $0.05 \mathrm{~V}$. Furthermore, the coverages of non-desorbed oxygenated species, $\mathrm{OH}_{\mathrm{ad}} / \mathrm{O}_{\mathrm{ad}}$, on Pt surface as a function of low potential limit are displayed in the insert of Figure $4 \mathrm{~d}$. We can find the coverages of the non-desorbed oxygenated species increased to 0.29 at a low potential limit of $0.60 \mathrm{~V}$, moreover, this value might be higher under ORR conditions. Due to the fact that the non-desorbed oxygenated species will further block the $\mathrm{O}_{2}$ adsorption and reduction during positive going scan, so the ORR activities decreased significantly with the increasing of low potential limits and cyclic time. This results can be explained reasonably well based on our conjecture. 
a)
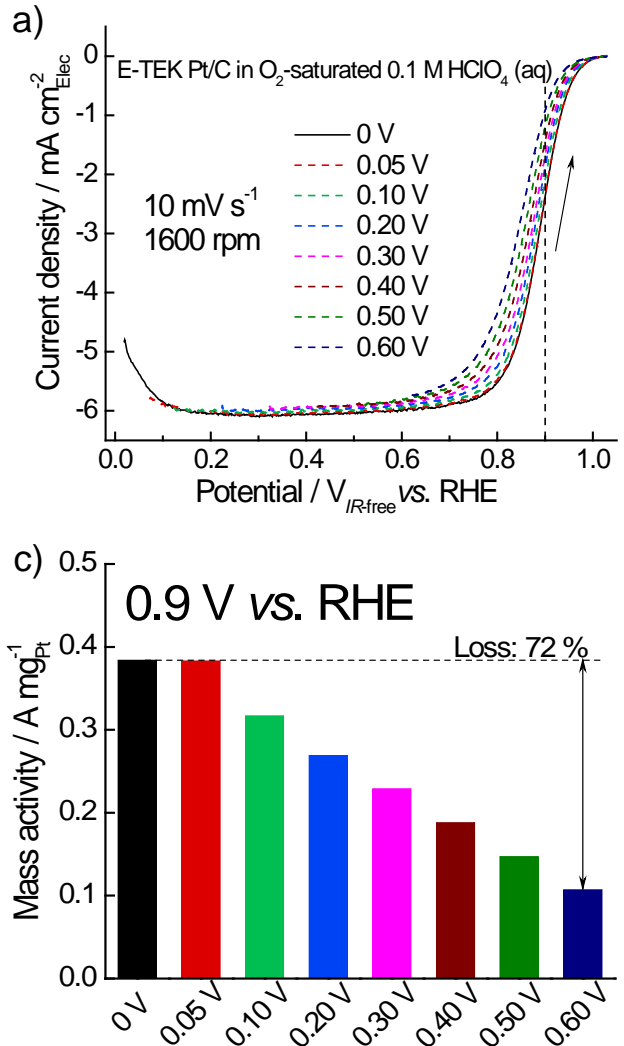

b)

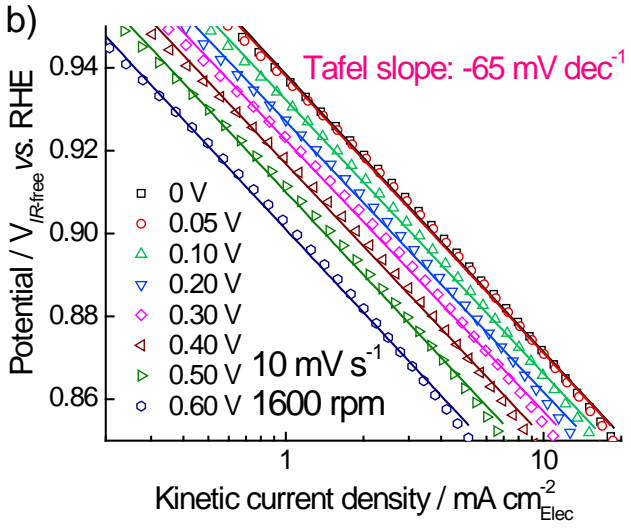

d) $0.2\left[\right.$ E-TEK Pt/C in Ar-saturated $0.1 \mathrm{M} \mathrm{HClO}_{4}(\mathrm{aq})$

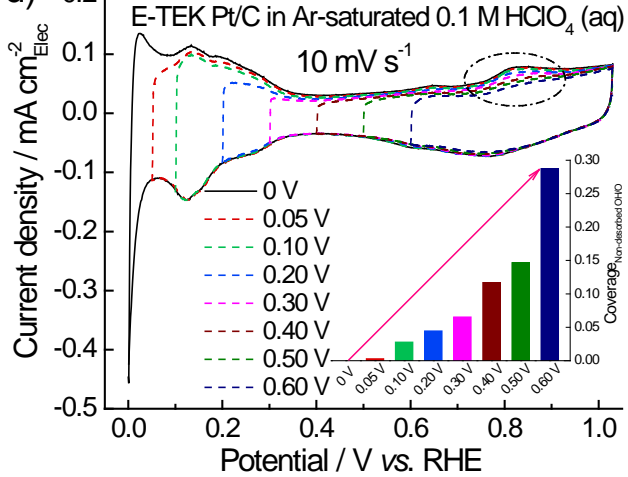

Figure 4. (a) ORR polarization curves and (b) Tafel plots of TF-RDE|Pt/C measured at scan rate of $10 \mathrm{mV} \mathrm{s}^{-1}$, the electrode rotating speed of $1600 \mathrm{rpm}$ in $\mathrm{O}_{2}$-saturated $0.1 \mathrm{M} \mathrm{HClO}_{4}$ with a series of different low potential limits (the high potential limit is $1.03 \mathrm{~V}$ ). (c) MAs calculated from the current densities at $0.9 \mathrm{~V}$ highlighted by dashed line in Figure 4a. (d) their corresponding CVs with same scan-profiles for ORR polarization measured in Ar-saturated $0.1 \mathrm{M} \mathrm{HClO}_{4}(\mathrm{aq})$, with the coverages of non-desorbed oxygenated species on $\mathrm{Pt}$ surface as a functional of the different low potential limits in the inset. The coverages are calculated by the equation: $\left(Q_{0}-Q_{\chi}\right) / Q_{0}$, where $Q_{0}$ is the integrated charge of desorption of $\mathrm{OH}_{\mathrm{ad}} / \mathrm{O}_{\mathrm{ad}}$ with low potential limit at zero, $Q_{\chi}$ is the integrated charge of desorption of $\mathrm{OH}_{\mathrm{ad}} / \mathrm{O}_{\mathrm{ad}}$ with low potential limit at $\chi \mathrm{V}(\chi=0,0.05,0.1,0.2$, $0.3,0.4,0.5,0.6$, respectively).

In the following experiments, the low potential limit is fixed at $0.05 \mathrm{~V}$ to investigate the effects of five different high potential limits from the ORR equilibrium potential of $c a .1 .2 \mathrm{~V}$ to the usual activity evaluation potential of $0.9 \mathrm{~V}$. The corresponding ORR polarization curves and CVs are shown in Figure 5. Unsurprisingly, these five ORR curves overlap in positive scan direction in Figure 5a. This means all electroadsorbed oxygenated species are desorbed during the negative scanning with the low potential limit of $0.05 \mathrm{~V}$, and the ORR polarization in positive going scan is unaffected. It is worth pointing out that in our current ORR measurement, the effects of the oxidation of carbon support on the ORR activity were not observed, although previous studies demonstrated that carbon black, i.e., XC-72R, can be oxidized in acid solution, 
especially when the electrode potential is higher than $1.0 \mathrm{~V}$ [49]. This can be reasonably explained by the fact that the corrosion of carbon support should be very slow, at least inconspicuous in our experimental conditions (as it only took less than one hour to study the effects of high potential limits, moreover, the highest potential is no more than $1.20 \mathrm{~V}$ ) because the carbon corrosion is generally caused by start-up and shut-down processes and/or long-term stability test [50-52]. Figure 5b shows that the CV curves overlapped in positive-going scan, although larger reduction peaks of oxidation region with higher high potential limits were observed. However, the ORR polarization curves in negative-going scan are strongly dependent on the high potential limits. The corresponding MAs at $0.9 \mathrm{~V}$ (inset in Figure 5a) decrease in sequence. The higher potential limits lead to the lower ORR activities due to higher coverages of electroadsorbed oxygenated species on catalyst surface. As we stated in section 3.1, the ORR polarization curve in positive scan direction from a very low potential to OCP is recommended to screen electrocatalysts in order to guarantee the reliability of the results.
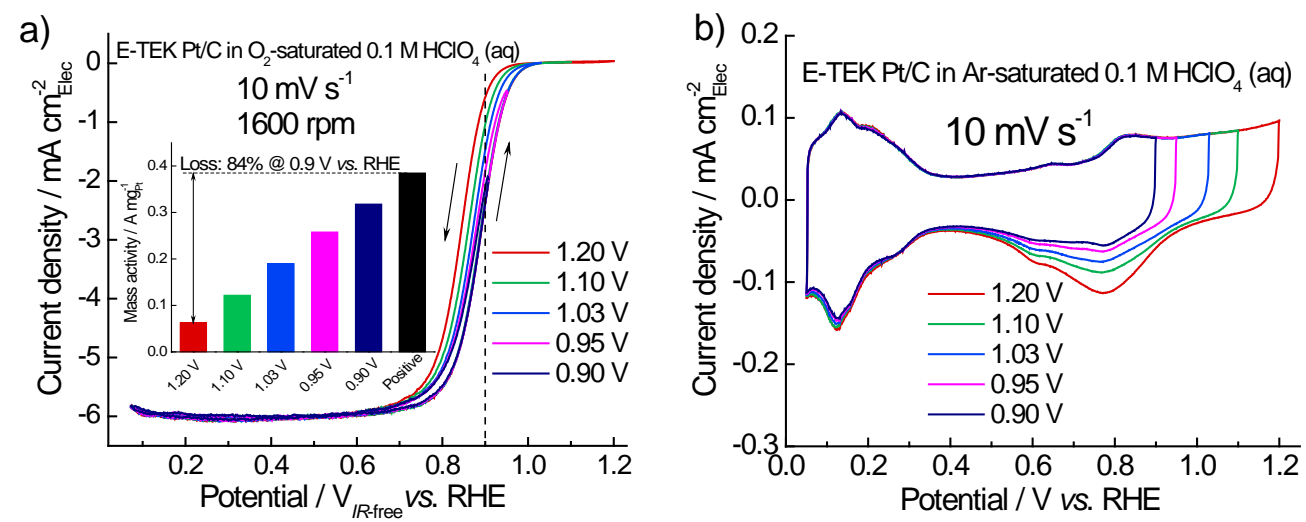

Figure 5. (a) ORR polarization curves of TF-RDE $\mid \mathrm{Pt} / \mathrm{C}$ measured at scan rate of $10 \mathrm{mV} \mathrm{s}^{-1}$, the electrode rotating speed of $1600 \mathrm{rpm}$ in $\mathrm{O}_{2}$-saturated $0.1 \mathrm{M} \mathrm{HClO}_{4}(\mathrm{aq})$ with a series of different high potential limits (the low potential limit is $0.05 \mathrm{~V}$ ) with the MAs calculated from the current densities at $0.9 \mathrm{~V}$ highlighted by dashed line in the inset, and (b) their corresponding CVs with same scan-profiles for ORR polarization measured in Ar-saturated $0.1 \mathrm{M} \mathrm{HClO}_{4}(\mathrm{aq})$.

\subsubsection{The effects of potentiodynamic parameters on ORR kinetics of bulk Pt}

Based on the above results, the ORR polarization behavior of the nano-sized electrocatalysts strongly depends on the associated potentiodynamic parameters when using the TF-RDE technique to pre-evaluate their catalytic activities. Although the electrocatalyst film on glassy 
carbon electrode is very thin (i.e., $<1 \mu \mathrm{m}$ ) so that the oxygen diffusion resistance can be negligible [17], it is still a porous coating and owns a longitudinal gradient from glassy carbon substrate to the surface of thin-film at micro level. These properties might cause the inhomogeneous imposed potential and electrochemical responses hysteretic inside of this thin-film, and lead to ORR activities appeared strongly depend on potentiodynamic parameters.

In order to study this possibility, we further investigate the ORR of smooth bulk Pt. Moreover, to avoid the interference of contaminations in electrolyte as much as possible, we performed measurements using scan rates ten times higher than that used for TF-RDE|Pt/C. As shown in Figure 6, identical experimental phenomenon with TF-RDE was observed for bulk Pt. The potentials of ORR polarization curves of bulk Pt shift positively; however, the corresponding capacities for $\mathrm{OH}_{\mathrm{ad}}$ adsorption/desorption change in reverse trends with the increase of scan rate from 50 to $500 \mathrm{mV} \mathrm{s}^{-1}$, as shown in Figure 6a and b. Figure 6c and d depict the effects of low potential limits on the ORR polarization and voltammetric behaviors for bulk Pt, respectively. We can observe more clearly from the local enlarged curves inserted in respective figures, the trends are almost identical with the case of TF-RDE|Pt/C. The last not the least, the measurements with different high potential limits are performed. The ORR polarization curves and CVs in Figure 6e and f, show the expected change.

The ORR polarization of the smooth bulk Pt also exhibits identical electrochemial behaviors, which indicates that the dependency of measured ORR kinetics on potentiodynamic parameters is not relevant to the oxygen diffusion and/or the electrode structure. This was further evidence proving that it is reliable using TF-RDE method technique to pre-evaluate the ORR activities of nano-sized electrocatalysts. 
a)

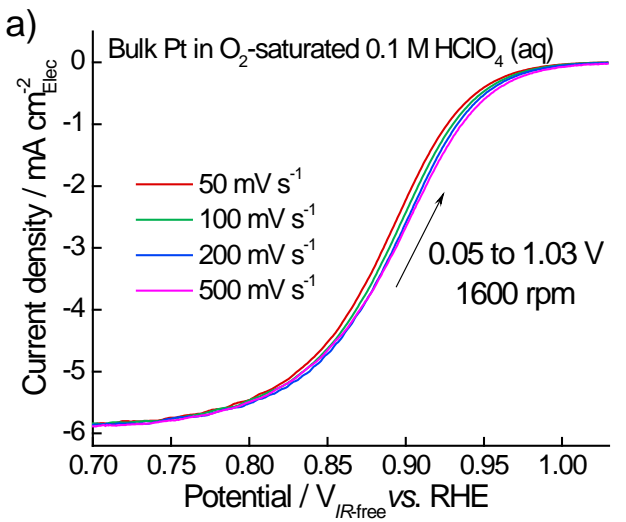

c)

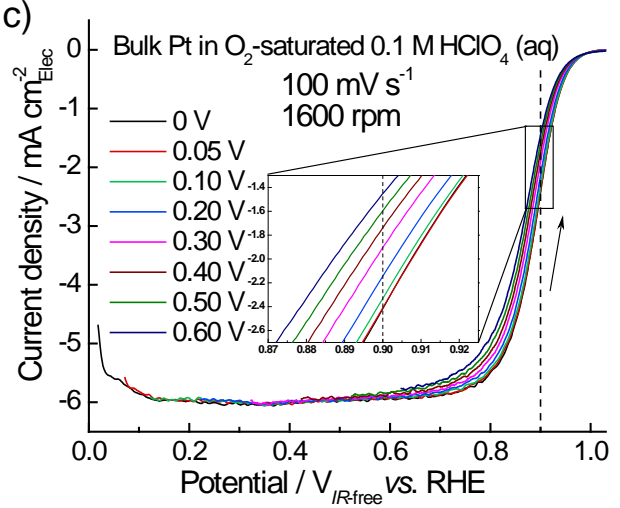

e)

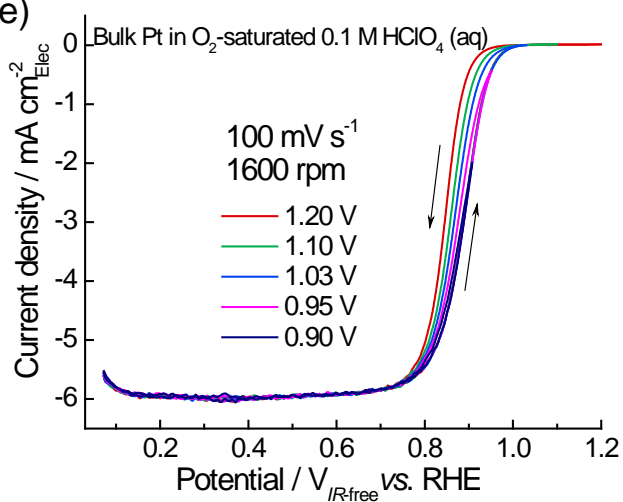

b)

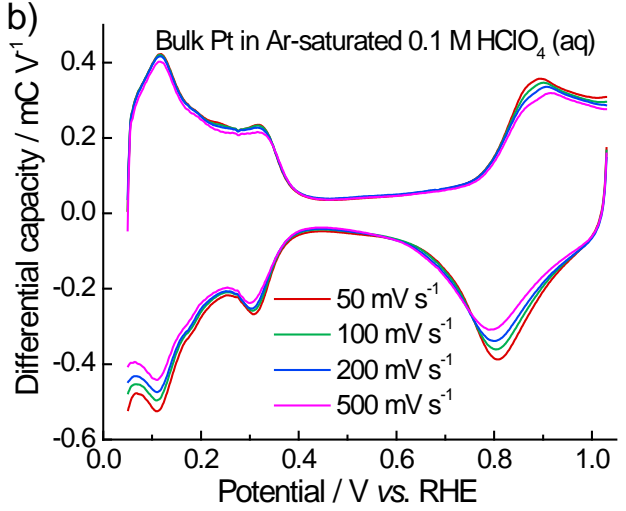

d)
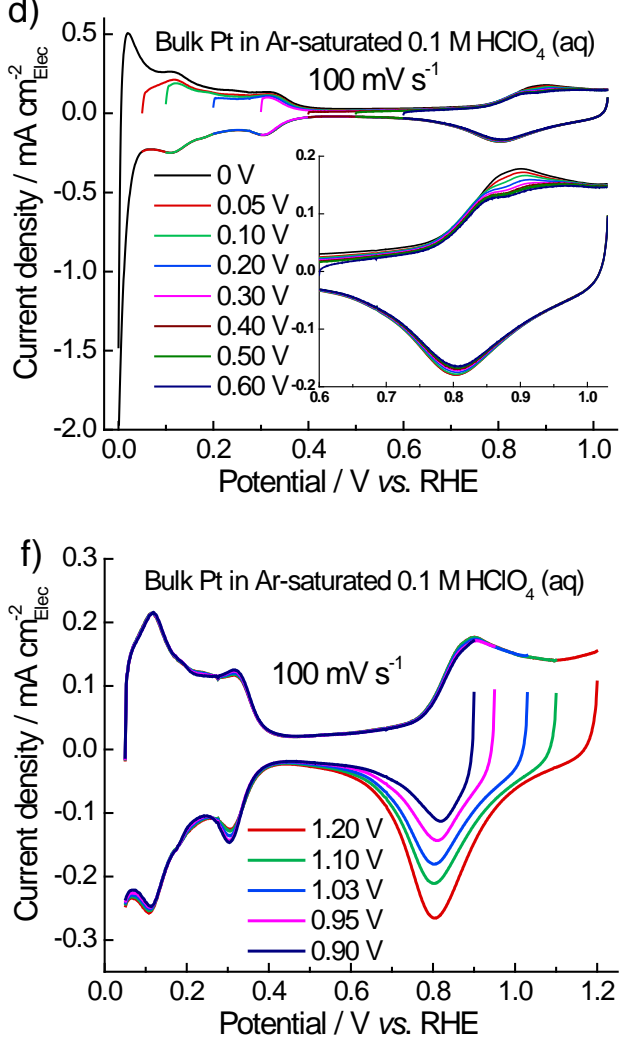

Figure 6. (a) ORR polarization curves with different scan rates and (b) their corresponding CVs normalized to the scan rates. (c) ORR polarization curves with a series of different low potential limits (the high potential limit is $1.03 \mathrm{~V}$ ) and (d) their corresponding CVs. (e) ORR polarization curves with a series of different high potential limits (the low potential limit is $0.05 \mathrm{~V}$ ) and (f) their corresponding CVs. The working electrode is bulk Pt. All ORR measurements were performed at the electrode rotating speed of 1600 rpm in $\mathrm{O}_{2}$-saturated $0.1 \mathrm{M} \mathrm{HClO}_{4}$ (aq). All CVs were measured in Ar-saturated 0.1 $\mathrm{M} \mathrm{HClO}_{4}$ (aq).

\subsection{Further analyses of the desorption of oxygen-containing species on Pt surface}

It is generally accepted that the electroadsorbed oxygenated species on Pt surface are reduced completely at $c a$. $0.4 \mathrm{~V}$, which is the onset potential of H-UPD; however, our above results indicate that the electroadsorbed $\mathrm{OH}_{\mathrm{ad}} / \mathrm{O}_{\mathrm{ad}}$ species on the Pt surface cannot be desorbed 
completely even inside H-UPD region. One evidence is the coverage of the non-desorbed oxygenated species on surface of nano-sized Pt is $~ 3 \%$ when the potential is scanned negatively from 1.03 to $0.20 \mathrm{~V}$ (refer to Figure 4d). In addition, we integrated the coulombic charge associated with the electroadsorbed oxygenated species on bulk Pt surface during both the positive and negative scan directions to the serial potentials, and the results are displayed in Figure 7a. Following the positive scanning, when the electrode is scanned negatively to the potential with a minimum current density (absolute value), $0.45 \mathrm{~V}$, the residual charge ratio of electroadsorbed oxygenated species is $3.4 \%$. Furthermore, we also found that during the CV scan between $0.10 \mathrm{~V}$ and $1.03 \mathrm{~V}$, the $\mathrm{CV}$ profile in subsequent positive scanning is back to that of clean surface, after the electrode potential being held at $0.10 \mathrm{~V}$ for 30 seconds (Figure $7 \mathrm{~b}$ ). These phenomena reflect that the adsorption/desorption of oxygenated species on Pt surface is seriously irreversible, perhaps because the subsurface $\mathrm{O}_{\mathrm{ad}}$ cannot be removed totally without reaching a very low potential or holding enough long time at low potential [38]. Our experimental result shows the low potential limit must be down to $0 \sim 0.05 \mathrm{~V}$ to remove all electroadsorbed oxygenated species on both nano-sized Pt surface and bulk Pt surface.

At present, we only can rely on indirect means, like used above, to explain this phenomenon. Advanced physical characterization methods combined with in-situ electrochemistry need to be developed to further investigate the adsorption/desorption behavior of oxygenated species on metallic surface.
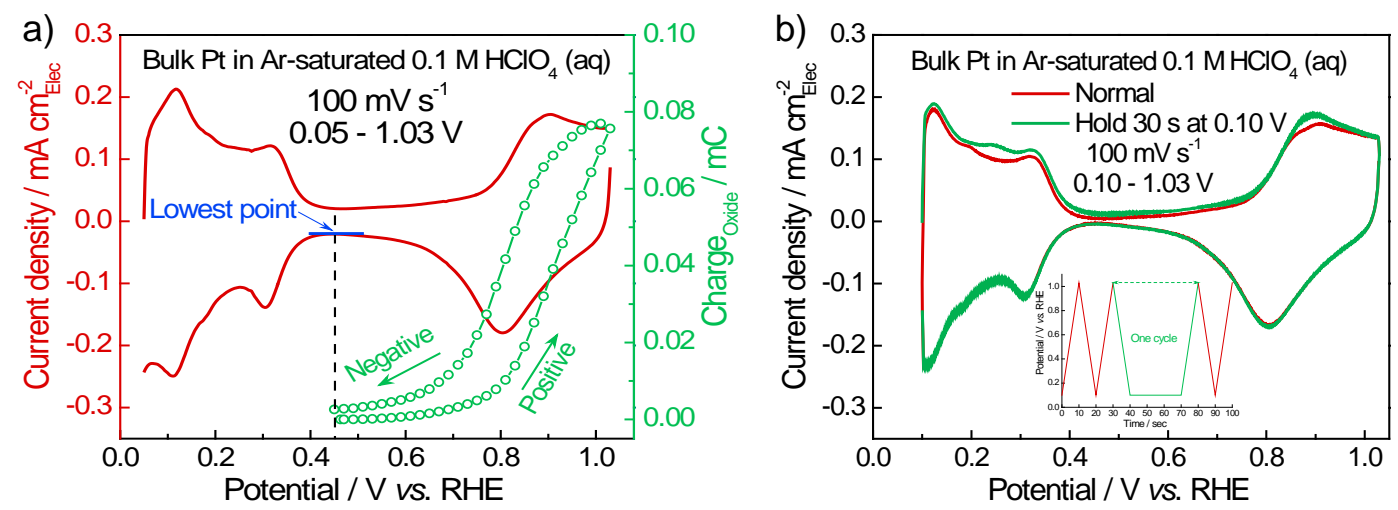

Figure 7. (a) $\mathrm{CV}$ of bulk Pt measured at a scan rate $100 \mathrm{mV} \mathrm{s}^{-1}$ in Ar-saturated $0.1 \mathrm{M} \mathrm{HClO}_{4}$ and the corresponding coulombic charge associated with the electroadsorbed oxygenated species on bulk Pt surface. (b) $\mathrm{CV}$ of bulk Pt measured in Ar-saturated $0.1 \mathrm{M} \mathrm{HClO}_{4}$ (aq) with a programmed potential scan profile inserted. 


\section{Conclusions}

Electrochemical polarization methods and related factors for ORR measurement in TF-RDE system were studied thoroughly in this work. We demonstrated that potentiostatic step method is unsuitable to be used in TF-RDE system to evaluate the ORR activities of nano-sized electrocatalysts. On the other hand, a stable and reproducible potentiodynamic-polarization curve can be measured by cyclic voltammetry, but the thin-film quality, impurities level and inevitable errors must be carefully controlled to achieve accurate results. Further investigation revealed that the ORR activities of both nano-sized and bulk Pt exhibited strong dependency on scan parameters due to the varying coverage of electroadsorbed oxygenated species but without impacting the overall ORR mechanism. We believe that this result is applicable to other metal-based electrocatalysts as well.

TF-RDE methodology has been commonly used to evaluate the ORR activities of electrocatalysts. Based on our research, we found that it is not feasible to perform comparison of ORR activities measured with different potentiodynamic parameters; therefore, it is necessary to establish a unified potentiodynamic polarization protocol for accurate pre-evaluation and easy comparison of new ORR electrocatalysts in TF-RDE system. The following parameters are suggested as a reference: scan rate: $10 \mathrm{mV} \mathrm{s}^{-1}$; scan region: 0 0.05 V to OCP $(1.00 \sim 1.05 \mathrm{~V})$.

\section{Notes}

The authors declare no competing financial interest.

\section{Acknowledgements}

This research was supported by the US Department of Energy, Office of Basic Energy Science, Material Science and Engineering Division, Division of Chemical Sciences, Geosciences and Biosciences Division, under the Contract No. DE-SC0012704, and by the 
National Natural Science Foundation of China (Project No. 21276058 and 21433003) and State Key Laboratory of Urban Water Resource and Environment, Harbin Institute of Technology (Project No. 2014DX10). G. Y. Chen acknowledges the financial support from both the China Scholarship Council and Brookhaven National Laboratory (BNL) to perform his work at BNL.

\section{References}

1. R.R. Adzic, F.H.B. Lima, in Handbook of Fuel Cell: Fundamentals, Technology and Applications, vol. 5, ed. by W. Vielstich, A. Lamm, H.A. Gasteiger, H. Yokokawa (John Wiley \& Sons, Chichester, 2010), p. 5

2. R.R. Adzic, in Electrocatalysis, vol. 5, ed. by J. Lipkowski, P.N. Ross (VCH Publishers, New York, 1998), p. 197

3. H.A. Gasteiger, S.S. Kocha, B. Sompalli, F.T. Wagner, Appl Catal B-Environ 56, 9 (2005)

4. M.K. Debe, Nature 486, 43 (2012)

5. J.X. Wang, N.M. Markovic, R.R. Adzic, J Phys Chem B 108, 4127 (2004)

6. J.L. Zhang, M.B. Vukmirovic, Y. Xu, M. Mavrikakis, R.R. Adzic, Angew Chem Int Edit 44, $2132(2005)$

7. V.R. Stamenkovic, B.S. Mun, K.J.J. Mayrhofer, P.N. Ross, N.M. Markovic, J. Rossmeisl, J. Greeley, J.K. Norskov, Angew Chem Int Edit 45, 2897 (2006)

8. V.R. Stamenkovic, B. Fowler, B.S. Mun, G.F. Wang, P.N. Ross, C.A. Lucas, N.M. Markovic, Science 315, 493 (2007)

9. V.R. Stamenkovic, B.S. Mun, M. Arenz, K.J.J. Mayrhofer, C.A. Lucas, G.F. Wang, P.N. Ross, N.M. Markovic, Nat Mater 6, 241 (2007)

10. N.M. Markovic, P.N. Ross, Surf Sci Rep, 45, 121 (2002)

11. S. Gottesfeld, ECS Trans 6, 51 (2008)

12. J. Greeley, I.E.L. Stephens, A.S. Bondarenko, T.P. Johansson, H.A. Hansen, T.F. Jaramillo, J. Rossmeisl, I. Chorkendorff, J.K. Norskov, Nat Chem 1, 552 (2009)

13. J.K. Norskov, J. Rossmeisl, A. Logadottir, L. Lindqvist, J.R. Kitchin, T. Bligaard, H. Jonsson, J Phys Chem B 108, 17886 (2004) 
14. R.R. Adzic, in Structural Effects in Electrocatalysis and Oxygen Electrochemistry, Proceedings, vol. 92-11, ed. by D.D. Scherson, D. Tryk, X. Xing (The Electrochem Soc Inc, Pennington, 1992), p. 419

15. N. Bonnet, M. Otani, O. Sugino, J Phys Chem C 118, 13638 (2014)

16. I.E.L. Stephens, A.S. Bondarenko, F.J. Perez-Alonso, F. Calle-Vallejo, L. Bech, T.P. Johansson, A.K. Jepsen, R. Frydendal, B.P. Knudsen, J. Rossmeisl, I. Chorkendorff, J Am Chem Soc 133, 5485 (2011)

17. T.J, Schmidt, H.A. Gasteiger, in Handbook of Fuel Cell: Fundamentals, Technology and Applications, vol. 2, ed. by W. Vielstich, A. Lamm, H.A. Gasteiger (John Wiley \& Sons, Chichester, 2003), p. 316

18. K.J.J. Mayrhofer, D. Strmcnik, B.B. Blizanac, V. Stamenkovic, M. Arenz, N.M. Markovic, Electrochim Acta 53, 3181 (2008)

19. Y. Garsany, O.A. Baturina, K.E. Swider-Lyons, S.S. Kocha, Anal Chem 82, 6321 (2010)

20. A.J. Bard, L.R. Faulkner, Electrochem. Methods: Fundamentals and Application, 2nd edn. (John Wiley \& Sons, New York, 2000), pp. 335-344

21. K. Ke, K. Hiroshima, Y. Kamitaka, T. Hatanaka, Y. Morimoto, Electrochim Acta 72, 120 (2012)

22. K. Shinozaki, B.S. Pivovar, S.S. Kocha, ECS Trans 58, 15 (2013)

23. I. Takahashi, S.S. Kocha, J Power Sources 195, 6312 (2010)

24. S.S. Kocha, J.W. Zack, S.M. Alia, K.C. Neyerlin, B.S. Pivovar, ECS Trans 50, 1475 (2013)

25. Y. Garsany, J.J. Ge, J. St-Pierre, R. Rocheleau, K.E. Swider-Lyons, J Electrochem Soc 161, F628 (2014)

26. E. Fabbri, S. Taylor, A. Rabis, P. Levecque, O. Conrad, R. Kotz, T.J. Schmidt, Chemcatchem 6, 1410 (2014)

27. E. Higuchi, H. Uchida, M. Watanabe, J Electroanal Chem 583, 69 (2005)

28. I.A. Pasti, N.M. Gavrilov, S.V. Mentus, Int J Electrochem Sci 7, 11076 (2012)

29. K. Shinozaki, J.W. Zack, R.M. Richards, B.S. Pivovar, S.S. Kocha, J Electrochem Soc 162, F1144 (2015) 
30. D. van der Vliet, D.S. Strmcnik, C. Wang, V.R. Stamenkovic, N.M. Markovic, M.T.M. Koper, J Electroanal Chem 647, 29 (2010)

31. V. Colic, J. Tymoczko, A. Maljusch, A. Ganassin, W. Schuhmann, A.S. Bandarenka, Chemelectrochem 2, 143 (2015)

32. H.A. Gasteiger, W. Gu, R. Makharia, M.F. Mathias, B. Sompalli, in Handbook of Fuel Cell: Fundamentals, Technology and Applications, vol. 3, ed. by W. Vielstich, A. Lamm, H.A. Gasteiger (John Wiley \& Sons, Chichester, 2003), p. 593

33. The US Department of Energy (DOE). Fuel Cell Technologies Office Multi-year Research, Development, and Demonstration Plan. http://energy.gov/sites/prod/files/2014/12/f19/fcto_myrdd_fuel_cells.pdf (2014)

34. The U.S. DRIVE Fuel Cell technical team. Cell Component Accelerated Stress Test and Polarization Curve Protocols for PEM Fuel Cells. http://www.uscar.org/guest/teams/17/U-S-DRIVE-Fuel-Cell-Tech-Team (2013)

35. S. Jomori, K. Komatsubara, N. Nonoyama, M. Kato, T. Yoshida, ECS Trans 58, 1457 (2013)

36. N.P. Subramanian, T.A. Greszler, J. Zhang, W. Gu, R. Makharia, J Electrochem Soc 159, B531 (2012)

37. F.A. Uribe, T.A. Zawodzinski, Electrochim Acta 47, 3799 (2002)

38. B.E. Conway, B. Barnett, H. Angersteinkozlowska, B.V. Tilak, J Chem Phys 93, 8361 (1990)

39. A. Kongkanand, J.M. Ziegelbauer, J Phys Chem C 116, 3684 (2012)

40. Y. Huang, J.L. Zhang, A. Kongkanand, F.T. Wagner, J.C.M. Li, J. Jorne, J Electrochem Soc 161, F10 (2014)

41. K. Kodama, R. Jinnouchi, T. Suzuki, T. Hatanaka, Y. Morimoto, Electrochim Acta 78, 592 (2012)

42. M. Arenz, V. Stamenkovic, T.J. Schmidt, K. Wandelt, P.N. Ross, N.M. Markovic, Surf Sci 523, 199 (2003)

43. P. Delahay, J Phys Chem 70, 2373 (1966)

44. K. Nisancioglu, J.S. Newman, J Electrochem Soc 159, E59 (2012) 
45. E.F. Holby, J. Greeley, D. Morgan, J Phys Chem C 116, 9942 (2012)

46. C.M. Pedersen, M. Escudero-Escribano, A. Velazquez-Palenzuela, L.H. Christensen, I. Chorkendorff, I.E.L. Stephens, Electrochim Acta 179, 647 (2015)

47. N. Hodnik, C. Baldizzone, S. Cherevko, A. Zeradjanin, K.J.J. Mayrhofer, Electrocatalysis 6, 237 (2015)

48. U.A. Paulus, T.J. Schmidt, H.A. Gasteiger, R. J. Behm, J Electroanal Chem 495, 134 (2001)

49. R. Srivastava, P. Strasser, ECS Trans 25, 565 (2009)

50. L. Dubau, M. Lopez-Haro, L. Castanheira, J. Durst, M. Chatenet, P. Bayle-Guillemaud, L. Guetaz, N. Caque, E. Rossinot, F. Maillard, Appl Catal B-Environ 142-143, 801 (2013)

51. H. Yano, T. Akiyama, P. Bele, H. Uchida, M. watanabe, Phys Chem Chem Phys 12, 3806 (2010)

52. S.R. Dhanushkodi, M. Tam, S. Kundu, M.W. Fowler, M.D. Pritzker, J Power Sources 240, 114 (2013) 